\title{
REMOVAL OF NICKEL AND COPPER FROM AQUEOUS SOLUTION BY SARGASSUM SP.TO REMEDIATES METAL CONTAMINATED INDUSTRIAL EFFLUENTS
}

\author{
A. Saravanan, T.V.N. Padmesh', Soundarajan Krishnan ${ }^{3}$ \\ ${ }^{1}$ Research Scholar, Department of Chemical Engineering, Sathyabama University, Chennai,India. \\ ${ }^{2,3}$ Department of Chemical Engineering, Sathyabama University,Chennai,India. \\ Email: saranbiotech2006@gmail.com
}

\begin{abstract}
Inorganic contaminants present in waste streams may be removed by one of three methods, viz. physical, chemical or biological. Chemical and physical techniques have traditionally been employed to remediate such streams. Biological structures such as bacteria, fungi, algae and others of higher structural complexity are potential adsorbents due to their abundant presence in the environment.Biosorbents derived from the biomass of marine algae have shown high uptake capacity for heavy metals.Biosorption, an inexpensive and reliable method to remove copper,zinc,nickel,chromium ions from solution. Dry sea weeds biomass used as adsorbents mainly because of its low cost and high metal binding capacity. In this work, the basic investigation is removal of copper and nickel ions from aqueous solution by Sargassum sp.Effects of algal biomass and medium $\mathrm{pH}$ on the metal ions were determined and optimized. Under the optimal conditions of the corresponding metal ions, the algal $\mathrm{Cu}^{2+}$ and $\mathrm{Ni}^{2+}$ were 51.11 and $63.54 \mathrm{mg} / \mathrm{g}$ respectively. The kinetic study revealed that the adsorption of $\mathrm{Cu}^{2+}$ and $\mathrm{Ni}^{2+}$ by Sargassum sp. fitted the Langmuir isotherm.
\end{abstract}

KEYWORDS: Biosorption, Copper, Nickel, Sargassum sp.

\section{INTRODUCTION}

Pollution of the environment by toxic heavy metals arises as a result of many activities, largely industrial although sources such as agriculture and sewage disposal also contribute (Matheickal and Yu,1999).All metal ion related industries produce waste water that contain metal ions and will cause pollution to aquatic bodies (Blackmore,1998). Heavy metals can be extremely toxic as they damage nerves,liver,kidney and bones and also block functional groups of vital enzymes (Carson et al,1986). For more than a decade, researchers have been looking for cheaper and more effective methods to remediate heavy metal contaminated waters and reduce the growing public health risk.

Biosorption is proven to be quite effective at removing metals ions from contaminated solution in a low-cost and environment-friendly manner (Volesky, 1990) The major advantages of biosorption over conventional treatment methods include low cost, high efficiency of metal removal from dilute solution, minimization of chemical and/or biological sludge, no additional nutrient requirement, regeneration of biosorbent and the possibility of metal recovery (Kratochvil and Volesky, 1998). Marine macroalgae are harvested or cultivated in many parts of the world and are therefore readily available in large quantities for the development of highly effective biosorbent materials.

Nickel, like the majority of heavy metals, is toxic but it has been widely used in metallurgical and tanning industries. Copper, one of the most widely used heavy metals, is mainly employed in electrical and electroplating industries, and in larger amounts is extremely toxic to living organisms. The presence of copper ions cause serious toxicological concerns, it is usually known to deposit in brain, skin, liver, pancreas and myocardium (Davis et al, 2000).

The objective of the present work was to evaluate copper and nickel biosorption by Sargassum sp., and also to evaluate the influence of different parameters on nickel and copper uptake such as sorption time, agitation speed, initial $\mathrm{pH}$, and initial ion concentration was investigated and the maximum biosorption capacity of the biomass, based on dry weight was determined from the equilibrium data measured under optimized conditions of $\mathrm{pH}$ and modeled according to Langmuir model.

\section{MATERIALS \& METHODS}

\section{A. Preparation of Biomass}

The biomass used in the present study was the brown sea weed Sargassum sp., collected from the southern coast of India. After harvesting from sea, the samples were washed with distilled water to remove particulate materials and salts from the surface. They were then dried in an oven at $60 \mathrm{c}$ for $24 \mathrm{hrs}$ and then used as biosorbent for further studies (Da costa and De franca,1997).

\section{B. Synthetic Effluent and Metal Ions Analysis}

Analytical grade $\mathrm{Nicl}_{2} \cdot 6 \mathrm{H}_{2} \mathrm{O}$ and $\mathrm{CuSO}_{4} \cdot 5 \mathrm{H}_{2} \mathrm{O}$ were dissolved in distilled water inorder to obtain a solution containing nickel and copper. This solution was used for metal biosorption experiments. Concentrations of standard and process solutions were evaluated by Atomic absorption spectrometry (AAS6VARIO; Analytik jena, Germany). 


\section{Batch Biosorption Studies}

All batch biosorption experiments were performed by adding $100 \mathrm{mg}$ of dried biomass to $100 \mathrm{ml}$ of metal solution in $250 \mathrm{ml}$ erlenmeyer flasks. The flasks were agitated at 150rpm. The experiments were conducted at room temperature. For studying the influence of $\mathrm{pH}$ on the biosorption,experiments were conducted at various initial metal solution $\mathrm{pH}$ values of 3-6.Algal mass quantity was varied from $20-100 \mathrm{mg}$ to know the optimal concentration of biosorbent.Metal free and biosorbent free blanks were used as control. The residual ion concentration in the solution was analyzed using atomic absorption spectrometry.

\section{Equilibrium Study of Metal Ion Adsorption by Sea Weed Biomass}

The empirical form of the Langmuir adsorption isotherm equation is given as:

$$
q_{e}=\frac{b C_{e} q_{\max }}{1+b c_{e}}
$$

$$
\frac{C_{e}}{q_{e}}=\frac{1}{q_{\max }} C_{e}+\frac{1}{q_{\max } b}
$$

Where $q_{e}$ is the removal capacity of metal $\mathrm{mg} / \mathrm{g} . \mathrm{C}_{\mathrm{e}}$ is the equilibrium concentration of metal ions in solution $\mathrm{mg} / \mathrm{L}, \mathrm{q}_{\max }$ is the maximum adsorption capacity (unit:mg/g or $\mathrm{mmol} / \mathrm{g}$ ), and $b$ is the affinity constant(unit:L/mg or $\mathrm{L} / \mathrm{mmol}$ ).

The Freundlich isotherm holds most of the assumptions suggested in Langmuir isotherms, except that it assumes that sorption takes place on a heterogeneous surface and the binding sites are not equivalent and/or independent (Aksu et al., 1999). In other words, if the data for adsorption from the solution fits the equation, it is possible that the surface is heterogeneous, although the model does not prove the fact soley (Adamson, 1982). The empirical Freundlich adsorption isotherm equation (Volesky, 1990) is given as:

$$
q_{e}=k C_{e}^{1 / n}
$$

This equation can be linearized by taking natural log (In) and given the following form:

$$
\ln \mathrm{q}_{\mathrm{e}}=\ln \mathrm{k}+-\mathrm{C}_{\mathrm{e}}
$$

Where $\mathrm{q}_{\mathrm{e}}$ is the removal capacity of metal $\mathrm{mg} / \mathrm{g}$, $\mathrm{k}$ is the adsorbent capacity and $\mathrm{l} / \mathrm{n}$ is the adsorption intensity.

\section{RESULTS AND DISCUSSION}

\section{E. Effect of Initial Solution Ph}

Marine algae contain high content of ionizable groups (carboxyl groups from mannuronic and guluronic acids) on the cell wall polysaccharides, which suggests that the biosorption process could be affected by changes in the solution pH (Davis et al., 2000., Matheickal and Yu, 1999). From figure1and 2 it was observed that, the uptake of copper and nickel showed a sharp increase with an increase in $\mathrm{pH}$ from 3.0 to 5.5. Hence, the strong $\mathrm{pH}$ dependence of copper and nickel biosorption was observed in this study.

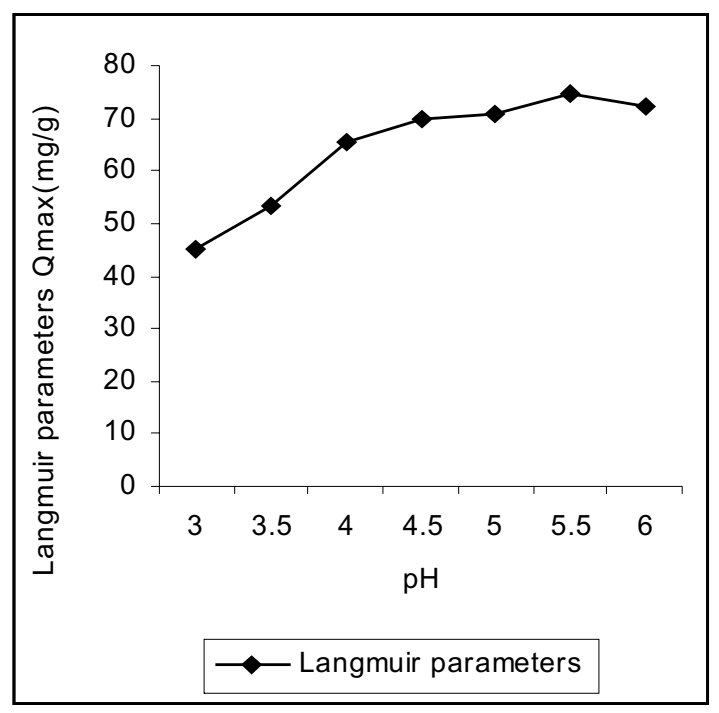

Fig. 1 Copper removal by Sargassum sp.at different pH conditions

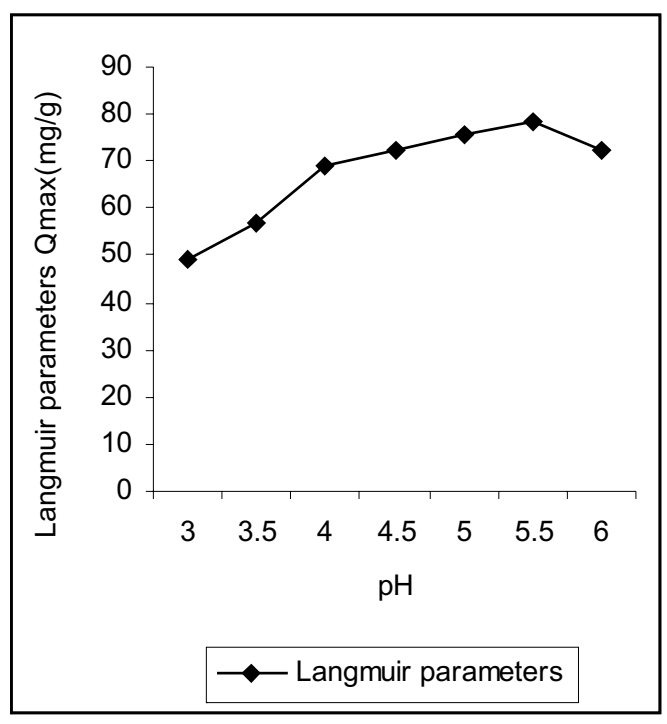

Fig. 2 Nickel removal by Sargassum sp.at different $\mathrm{pH}$ conditions 


\section{F. Effect of Algae Mass}

The effect of Sargassum sp. concentration (mass) on the removal of copper and nickel was studied using algal mass in the range of 20-100 mg.Figure 3 and 4 . Showed an increased uptake of ions with increase of alga quantity. The maximum uptake was attained at about $100 \mathrm{mg}$. This trend could be due to the formation of biosorbent aggregates at higher biomass concentration, which in turn could reduce the effective surface area available for the biosorption.

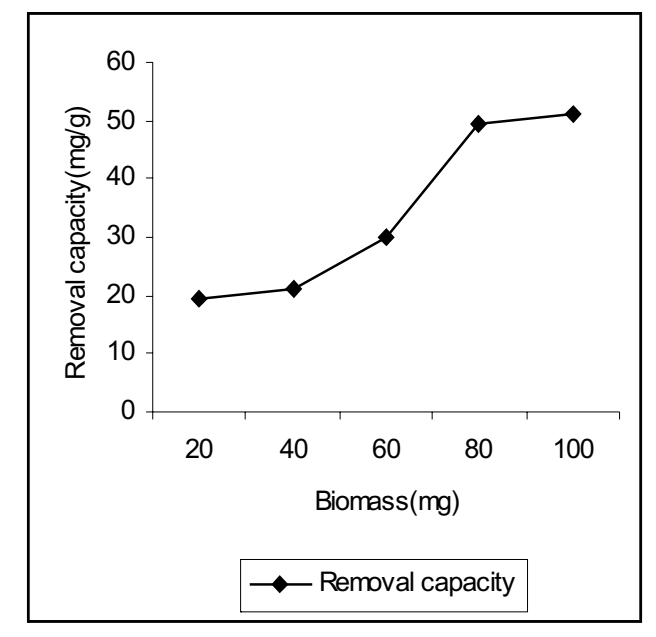

Fig. 3 Effect of algal mass on the removal of copper ions

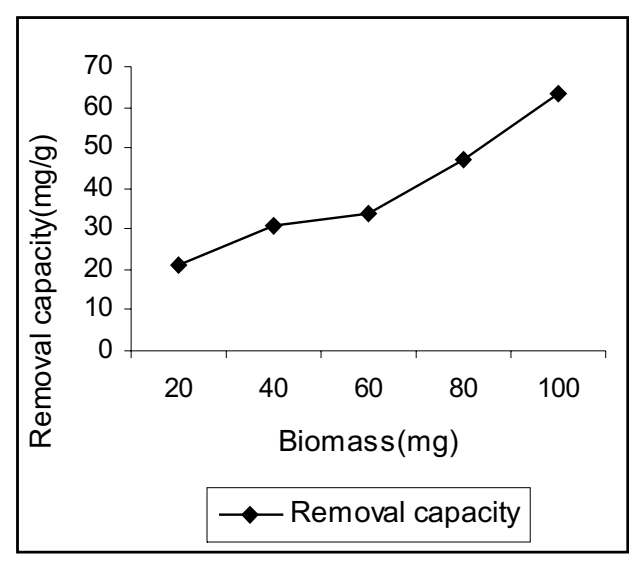

Fig. 4 Effect of algal mass on the removal of nickel ions

\section{G. Effect of Agitation Rate}

The uptake of copper and nickel ions by Sargassum sp. was evaluated varying the agitation rate from 0 250rpm.Fig 5 and 6 shows that copper and nickel uptake increases with the increase in shaking rate. The adsorption capacity of algae remained constant $(5.7 \mathrm{mg} / \mathrm{g}$ for copper and $6.9 \mathrm{mg} / \mathrm{g}$ for nickel) for agitation rates at 150 $\mathrm{rpm}$. The result indicates that a shaking rate in the range
$150 \mathrm{rpm}$ is sufficient to assure that all the cell wall binding sites are made readily available for metal uptake.

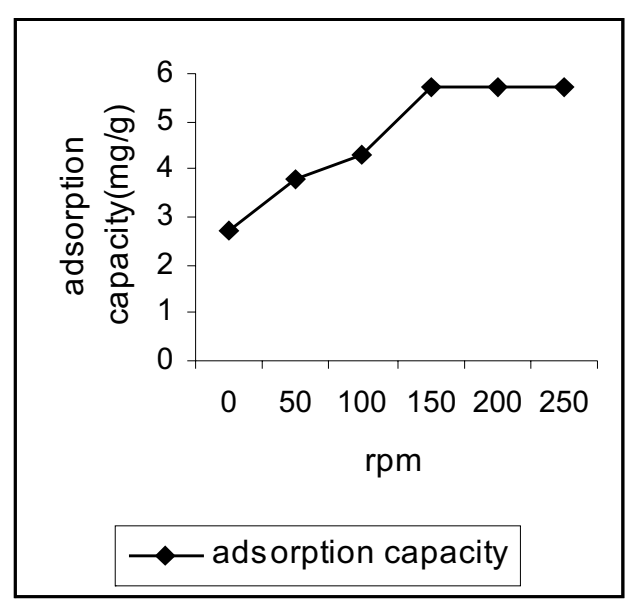

Fig. 5 Adsorption capacity of copper at different rpm

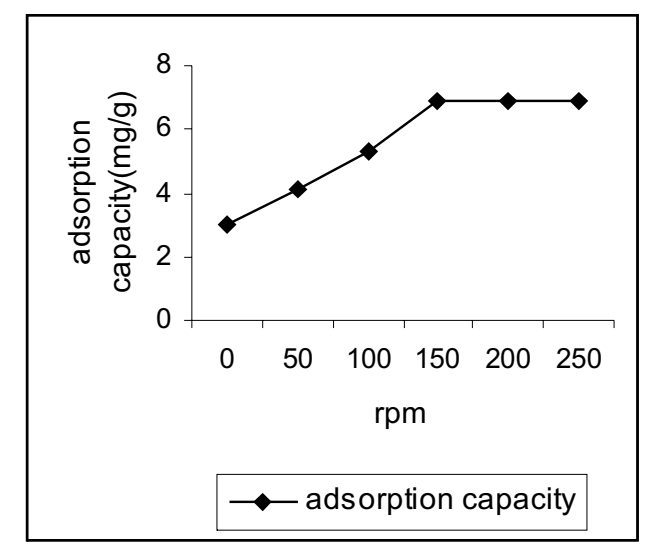

Fig. 6 Adsorption capacity of nickel at different rpm

\section{H. Equilibrium Study of Metal lon Adsorption}

The purpose of these experiments was to determine the contact time required to reach the equilibrium. Figure 7 and 8 show the results obtained in the kinetic tests of sorption for copper and nickel at different concentrations. The metallic ion fraction removed from solution was calculated by the following expression:

$$
f_{j}=\frac{\left(C_{j}^{0-} C_{j}(t)\right)}{\left(C_{j}^{0}-C_{j}^{*}\right)}
$$




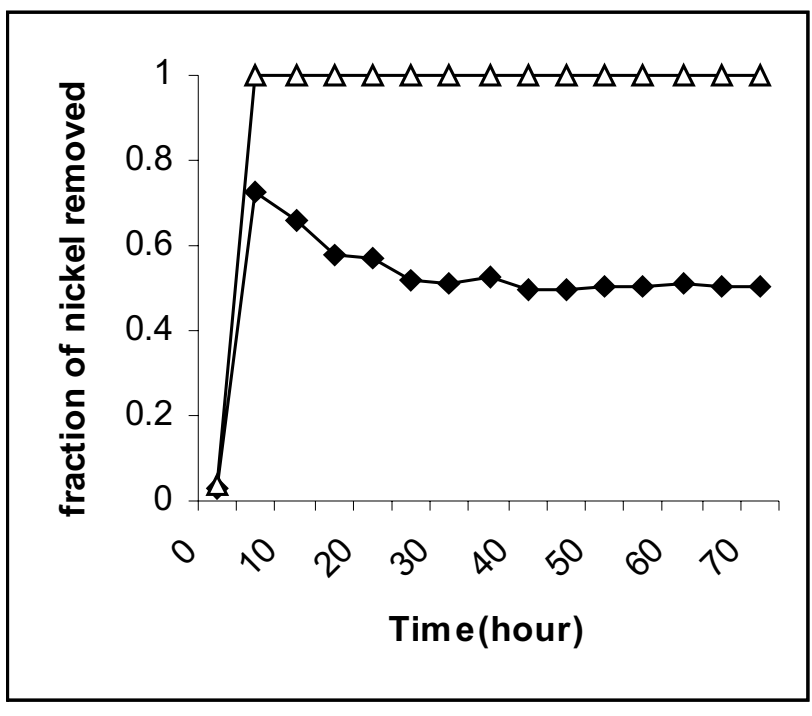

Fig. 7 Kinetics of nickel biosorption by Sargassum sp.

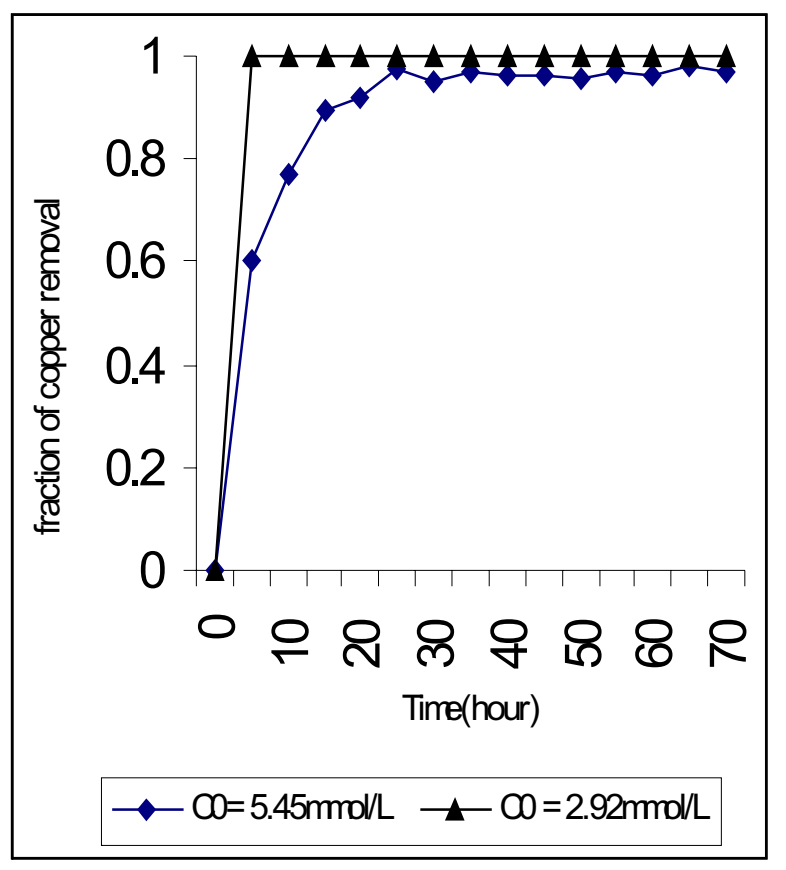

Fig. 8 Kinetics of copper biosorption by Sargassum sp.

From figure 7 and 8 it can be observed that copper removal is faster than nickel removal. The greater mobility of the copper ion is probably due to its smaller ionic radius. Contact time for equilibrium is a function of several factors: biomass type (number and types of metal-binding sites), size and forms of biomass, state of biomass (active or inactive, free or immobilized), etc. The results of kinetic biosorption tests showed that after 6 hours, approximately $70 \%$ of nickel had been removed when $\mathrm{C}^{0}=6.32 \mathrm{mmol} / \mathrm{L}$, and $80 \%$ whenC ${ }^{\circ}=3.10 \mathrm{mmol} / \mathrm{L}$. After 30 minutes, approximately $87 \%$ of the copper had been removed when $\mathrm{C}^{0}=5.45 \mathrm{mmol} / \mathrm{L}$, and $82 \%$ when $\mathrm{C}^{0}=2.92 \mathrm{mmol} / \mathrm{L}$.
However, irrespective of the value for initial concentration, the time required for the system to reach equilibrium was about the same.

From the result of kinetic tests it can be verified that a minimum contact time of 48 hours was necessary for the system to reach equilibrium. Thus, in the equilibrium experiments a contact time of 72 hours was allowed to guarantee that equilibrium would be reached. Based on Langmuir and Freundlich isotherm models, biomass of Sargassum sp. can be classified as a good biosorbent.

\section{SUMMARY AND CONCLUSION}

The present work evaluated the removal of copper(II) and nickel(II) from aqueous solution using Sargassum sp. biomass. The sorption capacity of copper and nickel was increased with increase in $\mathrm{pH}$ reaching a maximum at 5.5 . The Langmuir adsorption model described well the biosorption equilibrium of copper (II) and nickel (II) ions on Sargassum sp. Langmuir isotherm parameters were used to determine the affinity of one metal for the biosorbent in the presence of the other metal, showing that the nickel ion had a greater affinity for Sargassum sp. than the copperion.

\section{REFERENCES}

1] Aksu, Z Acikel, U.and Kutsal, T. Investigation of simultaneous biosorption of copper (II) and chromium(IV) on dried Chlorella vulgaris from binary metal mixtures: application of multicompon[ent adsorption isotherms. Seperation science and technology, 1999,vol.34,pp.501-524.

[2] Blackmore, G. An overview of trace metal pollution in the coastal wasters of HongKong. The science of the total environment., 1998,vol.214, pp.21-48.

[3] Carson,B.L.,Ellis, .V.andMcCann,J.L. Toxicology and biological monitoring of metals in humans, Lewis publishers, Michigan,1986,pp.71-133.

[4] Da costa, A.C.A. and De franca, F.P. Biosorption of zinc, cadmium and copper by a brown sea weed (Sargassum sp.) in a continuous fixed - bed laaboratory reactor. Bioseparation., 1997, vol.6, pp.335-341.

[5] Davis, T.A, Volesky, B.and Vieira, R.H.S.F Sargassum seaweed as biosorbent for heavy metals.Wat.Res.,2000,vol.34,pp.4270-4278. 
[6] Kratochvil. D. and Volesky, B. Advances in the biosorption of heavy metals. Trends Biotechnol., 1998,vol.16,pp.291-300.

[7] Matheickal, J.T. and Yu,O.Biosorption of Iead(II) and copper(II) by pre-treated biomass of Australian marine algae.Bioresource Tech., 1999, vol.69, pp.223-229.

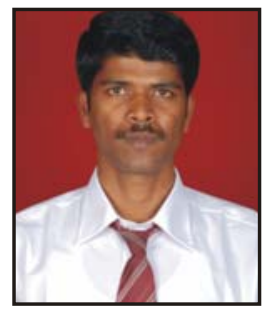

Mr.Saravanan. A is currently working as a lecturer in the Department of Chemical Engineering,Sathyabama University, Chennai. He has published his work in 2 international journal,1 international conference and1 national conference

[8] Volesky,B. Biosorption and biosorbents. In biosorption of heavy metals, CRC press, Florida,1990,pp.3-6.

1] Aksu, Z Acikel, U.and Kutsal, T. Investigation of simultaneous biosorption of copper (II) and chromium(IV) on dried Chlorella vulgaris from binary metal mixtures: application of multicompon[ent adsorption isotherms. Seperation science and technology, 1999,vol.34,pp.501-524.

[2] Blackmore, G. An overview of trace metal pollution in the coastal wasters of HongKong. The science of the total environment., 1998,vol.214, pp.21-48.

[3] Carson,B.L.,Ellis, .V.andMcCann,J.L. Toxicology and biological monitoring of metals in humans, Lewis publishers, Michigan,1986,pp.71-133.

[4] Da costa,A.C.A. and De franca, F.P. Biosorption of zinc, cadmium and copper by a brown sea weed (Sargassum sp.) in a continuous fixed - bed laaboratory reactor. Bioseparation., 1997, vol.6, pp.335-341. 